\title{
A IMPORTAÇÃO DE TEORIAS EURO-AMERICANAS NO DIREITO BRASILEIRO COMO REVÉS AO PROJETO EMANCIPADOR DO PLURALISMO JURÍDICO PRESENTE NO CONSTITUCIONALISMO LATINO AMERICANO
}

\author{
THE IMPORTATION OF EURO-AMERICAN THEORIES IN BRAZILIAN LAW AS A REVERSE \\ TO THE EMANCIPATING PROJECT OF LEGAL PLURALISM PRESENT IN LATIN \\ AMERICAN CONSTITUTIONALISM
}

Talissa Truccolo Reato

\begin{abstract}
Doutoranda em Direito pela Universidade de Caxias do Sul (2019/). Bolsista Prosuc/CAPES (2019/).
Mestra em Direito pela Universidade de Passo Fundo (2016/2018). Taxista Prosup/CAPES (2016/2018). Realizou estância de pesquisa (atividades docentes e investigatórias) na Faculdade de Direito da Universidade de Sevilla - Espanha (2017). Especialista em Direito Processual pela Universidade Regional Integrada do Alto Uruguai e das Missões (2014/2015) - Pós-Graduação Lato Sensu. Graduada em Direito pela Universidade Regional Integrada do Alto Uruguai e das Missões (2009/2014).

E-mail: talissareato@ hotmail.com.
\end{abstract}

\section{Cleide Calgaro}

Pós-Doutora em Filosofia e em Direito ambos pela Pontifícia Universidade Católica do Rio Grande do Sul - PUCRS. Doutora em Ciências Sociais na Universidade do Vale do Rio dos Sinos - UNISINOS. Doutora em Filosofia pela Pontifícia Universidade Católica do Rio Grande do Sul - PUCRS, na condição de taxista CAPES. Doutoranda em Direito pela Universidade de Santa Cruz do Sul - UNISC. Mestra em Direito e em Filosofia pela Universidade de

Caxias do Sul - UCS. Atualmente é Professora da Graduação e Pós-Graduação em Direito na Universidade de

Caxias do Sul. É Líder do Grupo de Pesquisa "Metamorfose Jurídica" da Universidade de Caxias do Sul-UCS e Vice-Líder do Grupo de Pesquisa "Filosofia do Direito e Pensamento Político" da Universidade Federal da ParaíbaUFPB. Atua como pesquisadora no Grupo de pesquisa "Regulação ambiental da atividade econômica sustentável (REGA)" da Escola Superior Dom Helder Câmara e no CEDEUAM UNISALENTO - Centro Didattico Euroamericano sulle Politiche Costituzionali na Università del Salento-Itália. É membro do Comitê Assessor de Ciências Humanas e Sociais da FAPERGS: Membro Titular (2019-2021). E-mail: ccalgaro1@ @otmail.com

Recebido em: 07/03/2021

Aprovado em: 01/09/2021

RESUMO: Ciente de que Constituição da República Federativa do Brasil de 1988 pertence ao movimento do constitucionalismo da América Latina e que este afluxo evidencia o pluralismo jurídico, urge refletir sobre a ordem jurídica do Brasil, a qual ainda se submete às teorias, figuras e institutos externos para resolver problemas internos. Sendo assim, a presente pesquisa questiona como a importação de teorias euro-americanas no direito brasileiro combate o empenho emancipador do pluralismo jurídico. Os temas centrais são: constitucionalismo latino-americano, pluralismo jurídico, importação de teorias jurídicas euro-americanas no direito brasileiro e consideração das nações brasileiras em prol da construção de instrumentos jurídicos próprios do Brasil. O objetivo geral é analisar como a importação de teorias euro-americanas no direito 
brasileiro atravanca a realização emancipadora do pluralismo jurídico conferido pelo constitucionalismo latino-americano. As considerações finais estão tecidas no sentido de que o Brasil precisa cicatrizar as feridas da época colonial para se libertar de asseverações externas, de modo que a adoção do pluralismo jurídico é um caminho para a referida emancipação, ou seja, sugere-se que no Brasil o direito seja dito a partir da cultura das várias nações que compõem o Estado brasileiro, sobretudo prestigiando criações internas. Metodologicamente a linguagem textual está posta via uma leitura sistemática. Usa-se o método hipotético-dedutivo. É uma análise exploratória e bibliográfica.

Palavras-chave: América Latina. Brasil. Emancipação. Constitucionalismo. Pluralismo Jurídico.

ABSTRACT: Aware that the 1988 Constitution of the Federative Republic of Brazil belongs to the movement of constitutionalism in Latin America and that this influx highlights legal pluralism, it is urgent to reflect on the legal order of Brazil, which is still subject to theories, figures and external institutes for solve internal problems. Therefore, the present research questions how the importation of Euro-American theories in Brazilian law combats the emancipatory commitment of legal pluralism. The central themes are: Latin American constitutionalism, legal pluralism, importation of Euro-American legal theories into Brazilian law and consideration by Brazilian nations in favor of the construction of Brazilian legal instruments. The general objective is to analyze how the importation of Euro-American theories into Brazilian law hinders the emancipatory realization of the legal pluralism conferred by Latin American constitutionalism. The final considerations are woven in the sense that Brazil needs to heal the wounds of the colonial era in order to free itself from external assertions, so that the adoption of legal pluralism is a path to the referred emancipation, that is, it is suggested that in Brazil the right is said based on the culture of the various nations that make up the Brazilian State, especially by honoring internal creations. Methodologically the textual language is put via a systematic reading. The hypothetical-deductive method is used. It is an exploratory and bibliographic analysis.

Keywords: Latin America. Brazil. Emancipation. Constitutionalism. Legal pluralism.

SUMÁRIO: Introdução. 1 O caráter emancipador do pluralismo jurídico no Brasil. 2 As consequências da fluente importação de Teorias Jurídicas Euro-Americanas no Direito Brasileiro. 3 A consideração das nações brasileiras em prol da construção de instrumentos jurídicos próprios do Brasil. Considerações finais. Referências.

\section{INTRODUÇÃO}

Observa-se que a Constituição da República Federativa do Brasil de 1988 pertence ao movimento do constitucionalismo da América Latina e que o reportado fenômeno jurídico avança no sentido de afixar o pluralismo jurídico, a presente pesquisa questiona de qual modo a importação de teorias euro-americanas no direito brasileiro combate o trabalho emancipador do pluralismo jurídico, tendo em vista que o constitucionalismo latino-americano abre portas para o pluralismo em comento, especialmente na terceira fase do movimento que envolve as Constituições do Equador e da Bolívia, enquanto que a ordem jurídica do Brasil insiste em se curvar (e relevar o conhecimento jurídico produzido a partir da variação cultural) diante de teorias, figuras e institutos externos para resolver problemas internos.

Exposto o problema que se intenta debater, passa-se para a fase de apresentação dos temas centrais envolvidos na pesquisa. Destarte, um dos conteúdos a ser abordado é o próprio constitucionalismo latino-americano (como um fenômeno que existe na América Latina após inúmeras ditaduras, visando avultar os direitos sociais a partir de uma nova perspectiva do direito, 
sobressaindo a cultura local). Outro tópico basilar, conectado ao constitucionalismo latinoamericano, é o pluralismo jurídico, que nada mais é do que reconhecer a existência e validar o direito consuetudinário, sobretudo indígena, na resolução de conflitos, afastando a jurisdição estatal como única possível, até mesmo porque o direito estatal brasileiro descende da cultura ocidental, não refletindo, portanto, muitas das características dos saberes locais.

Ademais, outros temas centrais são abordados, como as consequências da importação de teorias jurídicas euro-americanas no direito brasileiro, visto que a mencionada introdução pode causar adversidades, já que as teorias foram produzidas em contextos diferentes, ou seja, em Estados com grau de desenvolvimento distinto, o que culmina no fato de que nem sempre se adequam descomplicadamente à realidade brasileira. Por fim, o último tema central que não pode deixar de ser mencionado é a importância da consideração das nações brasileiras em prol da construção de instrumentos jurídicos próprios do Brasil, tendo em vista que não falta capacidade intelectual para que sejam construídas teorias, figuras e institutos brasileiros que não sejam reproduções estrangeiras adaptadas, mas que reflitam as características do Brasil.

Exibidos os temas centrais, passa-se aos objetivos da pesquisa. Em termos acessíveis, o objetivo geral é analisar como a importação de teorias euro-americanas no direito brasileiro atravanca a realização emancipadora do pluralismo jurídico conferido pelo constitucionalismo latino-americano. Assim, existem três objetivos específicos. O primeiro deles é reconhecer o caráter emancipador do pluralismo jurídico no Brasil. O objetivo seguinte não é outro senão avaliar as consequências da fluente importação de teorias jurídicas euro-americanas no direito brasileiro. Por fim, o terceiro desígnio visa compreender a relevância de considerar as nações brasileiras para a construção de instrumentos jurídicos próprios do Brasil.

Isto posto, a pesquisa se justifica porque no Brasil há um hábito de considerar o que é do exterior melhor, de modo que se pode acreditar que há um vício de autodepreciação, o qual afeta o próprio plano jurídico. Sendo assim, muitas teorias jurídicas produzidas em países europeus e norte-americanos são descontextualizadas para se adaptarem ao direito brasileiro, sendo que o Brasil também é capaz de desenvolver suas próprias soluções com base nas várias nações e culturas que existem no país. Para tanto, o pluralismo jurídico precisa ser avultado, isto é, necessita ser emancipado para que a riqueza da cultura brasileira não seja desvalida e sobreposta pelas ideias exteriores, que nem sempre condizem com a realidade do Brasil. Esta pesquisa pode ser considerada atual porque as Constituições do Equador (publicada em 2008) e da Bolívia (publicada em 2009) são recentes e abordam o pluralismo jurídico, de modo que a imediação temporal desta inovação constitucional, a proximidade territorial e a similaridade multicultural (considerando que referidos países também possuem diversas nações dentro do Estado) podem inspirar o Brasil a tomar coragem para despertar com as suas virtudes.

Quanto aos métodos de pesquisa, importa esclarecer que neste artigo a linguagem textual está posta via uma leitura sistemática. Usa-se o método hipotético-dedutivo porque se constroem conjecturas baseadas em hipóteses. Classifica-se esta pesquisa como básica (uma vez que gera conhecimentos de interesse universal). É uma análise exploratória, dado que utiliza levantamento bibliográfico. Por fim, com relação aos procedimentos técnicos se trata de uma pesquisa bibliográfica.

\section{O CARÁTER EMANCIPADOR DO PLURALISMO JURÍDICO NO BRASIL}

A fim de aferir o atributo emancipador da conquista que a admissão expressa do pluralismo jurídico teria no Brasil, importa, em primeiro lugar, compreender o fenômeno do pluralismo jurídico em um contexto mais amplo, o da América Latina, com ênfase, desde já, para os costumes dos povos indígenas. Destarte, inicia-se expondo que a diversidade cultural (tendo em consideração que uma cultura compreende aspectos sociais, mitológicos, religiosos, simbólicos, 
jurídicos, etc.) permite o reconhecimento de que cada sociedade possui maneiras particulares de se expressar, bem como de traduzir a realidade em seu entorno. Nesta óptica, contrapondo a proposta do direito estatal monista, introduz-se, como uma forma de garantir normas internas, a ideia do pluralismo jurídico (CURI, 2012, p. 238).

Assim, dois elementos podem ser erigidos como referenciais do pluralismo jurídico: um deles é o fato de que a realidade plural alude uma desigualdade fática que se manifesta em todos os aspectos da vida cotidiana, ainda que os valores contidos nas concepções dos vários grupos existentes estejam concebidos dentro das fronteiras de um mesmo país e relacionados por origens históricas; outro aspecto é a coexistência de pelo menos dois sistemas normativos em um mesmo espaço. Outrossim, o termo pluralismo significa qualidade do que não é único ou do que admite mais de uma categoria, de maneira que se caracteriza como sistema político que se baseia na concomitância de grupos diferentes e independentes. Portanto, a pluralidade se manifesta na existência e no reconhecimento das diferenças e, por decorrência, ao abordar o pluralismo se legitima a diversidade (CURI, 2012, p. 238-239).

Em outros termos, um conceito chave dos debates atuais sobre o direito é, então, o sentido e o alcance do pluralismo jurídico, particularmente do direito indígena. Este direito se inclui dentro de um grande grupo de direitos (não estatais), os quais são vislumbrados como se fossem informais, com um caráter ambíguo, até mesmo pejorativo, já que muitas vezes se afirma que existe um direito dominante, criado e sancionado pelo Estado (HOEKEMA, 2002, p. 67). Assim, não é incomum verificar posicionamentos no sentido que o direito estatal seria superior ao consuetudinário, uma vez que a jurisdição indígena, por exemplo, não se encontra em conformidade com os atributos herdados do modelo ocidental de dizer o direito.

No entanto, é preciso ter em conta que o direito estatal, embora predominante, não pode ser considerado como sendo o único adequado ou absoluto em um território dotado de diversidade de nações como é o caso da América Latina. Em outros termos, pode-se dizer que para a condução e a consolidação do pluralismo jurídico é importante que haja uma autêntica "descolonização, inclusive dos sistemas de justiça, suprimindo o locus privilegiado da justiça ordinária, como um dos passos necessários à emancipação e libertação das comunidades deste continente." (FERRAZZO, 2015, p. 23). Por conseguinte, pode-se tecer uma condensação no sentido que, conforme Antonio Carlos Wolkmer e Lucas Machado Fagundes (2011, p. 399), o pluralismo jurídico "conformado em núcleos de justiça comunitária é uma das formas de manifestação para além da juridicidade institucional operacionalizada pelo pensamento mecânico da cultura hegemônica (a cultura do homem moderno ocidentalizado)."

Ainda sobre o pluralismo jurídico na América Latina cabe reafirmar que os Estados latinoamericanos empregaram o modelo de direito europeu moderno, modelo que representa o produto de uma sociedade homogênea como sendo o único sistema jurídico aplicável para todos os cidadãos, criado e executado pelo Estado. Por conseguinte, as formas de resolução de conflitos utilizadas pelos indígenas (direito consuetudinário) era considerado um costume que precisava ser combatido e afastado para que os indígenas assimilassem a sociedade nacional. Contudo, tal aspiração não correspondeu à realidade, uma vez que grande parte dos Estados não são compostos por apenas uma nação, mas sim por várias nações, povos e etnias. Em suma, pode-se dizer que os Estados nacionais visam impor a unidade contra a diversidade e em face da pluralidade dos povos que a compõem e lutam pela manutenção de sua identidade (COLAÇO, 2015, p. 82).

Conforme Raquel Yrigoyen Fajardo (2004, p. 174), a fórmula utilizada pelos países da América Latina (Andinos) para o reconhecimento do direito consuetudinário ou indígena possui elementos e alcances semelhantes, com determinadas variações. $\mathrm{O}$ reconhecimento dos sistemas jurídicos indígenas possibilita uma articulação democrática com o sistema jurídico nacional e os poderes do Estado, além de permitir a redução da violência institucional. A fim de esclarecer melhor, pode-se afirmar que uma das principais conjunturas do pluralismo é o fato de que na América Latina as fórmulas constitucionais utilizadas geralmente incluem o reconhecimento de 
funções de justiça às autoridades das comunidades indígenas/camponesas, de acordo com o seu direito consuetudinário ou com as suas próprias normas e procedimentos no âmbito territorial de suas comunidades, ou seja, há o reconhecimento de órgãos indígenas de resolução de conflitos a partir de suas respectivas regras e procedimentos.

De acordo com Francisco Quintanilha Veras Neto (2015, p. 52) o pluralismo jurídico edifica uma teoria

da história e da práxis social que demonstra o caráter fetichista e ideológico do modelo do monismo jurídico emanado das grandes revoluções burguesas do século XVIII e XIX. Esta modelagem jurídica eurocêntrica cristalizou uma forma jurídica axiologicamente sustentada pela metanarrativa do positivismo jurídico de cunho tecnicista e conservador.

Neste sentido, "o tema do pluralismo jurídico deve se conectar, com as propostas de transformações sociais possíveis no atual cenário da globalização, dentro da busca de uma globalização alternativa, basista, pluralista e pós-colonialista" (VERÁS NETO, 2015, p. 74). Ademais, afirma-se que na América Latina o pluralismo jurídico sempre existiu por meio da manifestação do direito indígena desde o período colonial até o presente, sendo aceito ou não pelo Estado. Fato é que desde o primeiro contato, os colonizadores europeus não entenderam e não respeitaram as diferenças entre o direito ocidental e o direito consuetudinário dos povos indígenas, o qual se fundamenta na responsabilidade coletiva, no sistema de reciprocidade e solidariedade, priorizando os interesses coletivos sobre os individuais, o que é deveras diverso da sociedade burguesa individualista ocidental (COLAÇO, 2015, p. 80).

Retoma-se, então, a relevância do reconhecimento do pluralismo jurídico com caráter comunitário-participativo, uma vez que os seus elementos de efetividade (material e formal) abrem portas para, "ao mesmo tempo, provocar uma mudança nas relações sociais travadas, e permitir que novos esquemas de compreensão, interpretação e atuação no mundo se façam aparentes no espaço público e possam ressignificar" (SPAREMBERGER, 2015, p. 211). Isto posto, compreendido sem dilatação o tópico acerca do pluralismo jurídico, importa considerar o constitucionalismo brasileiro como integrante do movimento do constitucionalismo latinoamericano, conforme a classificação de Raquel Yrigoyen Fajardo.

Desta maneira, tratam-se de três ciclos de reformas constitucionais. O primeiro deles se desenvolveu durante os anos oitenta do século XX (anos de 1982-1988) e foi marcado pelo surgimento do multiculturalismo e pelas novas demandas indígenas. Foi neste período que as Constituições introduziram o conceito de diversidade cultural, bem como o reconhecimento da configuração multicultural e multilíngue da sociedade, o direito (individual e coletivo) à identidade cultural e alguns diretos indígenas específicos (FAJARDO, 2011, p. 141). O ciclo intermediário, pluricultural, desenvolveu-se nos anos noventa (1989-2005). As Constituições desta fase afirmaram o direito à identidade e à diversidade cultural e desenvolveram conceitos como de nação multicultural e de Estado pluricultural, qualificando a natureza da população e avançando para uma redefinição do caráter do Estado (FAJARDO, 2011, p. 142). O último ciclo de reformas dentro do horizonte pluralista é o constitucionalismo plurinacional, no qual se destacam o processo constituinte da Bolívia e do Equador, deu-se no contexto da aprovação da Declaração das Nações Unidas sobre os Direitos dos Povos Indígenas (FAJARDO, 2011, p. 149).

Neste viés, percebe-se que o pluralismo jurídico obteve notoriedade no último ciclo de reformas constitucionais na América Latina. Tendo em consideração que a Constituição do Brasil pertence à primeira etapa, pode-se refletir que não há no texto legal uma expressividade evidente sobre o pluralismo jurídico. No entanto, a existência de diversas nações no território nacional brasileiro, com destaque para as variadas culturas indígenas, permite reflexionar que existe um evidente potencial para o pluralismo jurídico se desenvolver com rigidez no Brasil, ainda que lentamente. 
A Constituição Federal do Brasil de 1988

em seus "Princípios Fundamentais" não faz referência ao estado plurinacional, nem ao pluralismo jurídico, e dispõe do Capítulo VIII - "Dos Índios", que possui dois artigos que tratam na sua maioria sobre as terras indígenas e a exploração de seus recursos naturais, mas não explicita o reconhecimento do direito indígena sob a perspectiva do pluralismo jurídico (COLAÇO, 2015, p. 90).

Poderia ser tecida a seguinte proposta de mudança no texto constitucional dos artigos $1^{\circ}$ da Carta brasileira: "A República Federativa do Brasil, formada pela união indissolúvel dos Estados e Municípios e do Distrito Federal, constitui-se em Estado Democrático de Direito Plurinacional e tem como fundamentos: [...] V - o pluralismo político e jurídico.” (COLAÇO, 2015, p. 90).

A admissão do pluralismo jurídico é uma conquista meio, ou seja, não é um êxito fim, uma vez que a luta pelo reconhecimento da existência de um pluralismo jurídico pelos Estados ainda revela uma superioridade da cultura jurídica advinda do racionalismo jurídico-positivista ocidental moderno. Fato é que o direito estatal, bem como os juristas formados sobre a lógica tecnoformalista precisam assimilar o que outras ciências já compreenderam: que o positivismo não é um trajeto a que todas as manifestações jurídicas devem chegar, de modo que ao invés de resolver impondo o direito estatal em nome da segurança jurídica, urge retomar as concepções de mitos, de não-linearidade temporal, de cosmovisões e de memórias coletivas a fim de que um diálogo intercultural seja possível (LUNELLI, 2015, p. 231).

Isto posto, quanto ao caráter emancipador do pluralismo jurídico, cumpre dizer que referido projeto, âncora de uma proposta coerente de consolidação democrática para a América Latina, só pode se basear em uma visão não instrumentalista do direito, segundo a qual as estruturas sociais e seus respectivos atores se encontram em constante mudança de influências e continuam se reorganizando, possibilitando uma reconstrução crítica da esfera jurídica em direção à reorganização do status político (WOLKMER, 2003, p. 11).

Pode-se entender, então, que o pluralismo jurídico, mesmo não disposto no texto da Constituição Federal do Brasil de 1988, é coerente e possui possibilidade de implantação no mencionado país, haja vista as diversas nações e culturas existentes. O caráter emancipador do pluralismo jurídico no Brasil detém a função de afastar a ideia de que a única jurisdição válida deve ser a importada-adaptada, visa mostrar que a cultura das comunidades indígenas deve ser respeitada e que, provavelmente, o direito consuetudinário seja mais satisfatório nas referidas comunidades do que o estatal. Emancipar é libertar, portanto, o jaez de desprendimento do pluralismo jurídico precisa ser considerado e aproveitado no Brasil.

\section{AS CONSEQUÊNCIAS DA FLUENTE IMPORTAÇÃO DE TEORIAS JURÍDICAS EURO-AMERICANAS NO DIREITO BRASILEIRO}

Observou-se que o pluralismo jurídico não é uma realidade expressa na Constituição Federal do Brasil, em que pese seja possível e desejado seu reconhecimento no referido país, tendo em conta que existem diversas nações dentro do território nacional, as quais, como é o caso do direito consuetudinário indígena, deveriam ter o seu potencial observado e respeitado. Acontece que o direito brasileiro importou e adaptou a jurisdição estatal como sendo a única aceita e, além do mais, o direito nacional segue, por excelência, a estrutura ocidental.

Deste modo, a dogmática brasileira continua a mesma dos últimos quinhentos anos: adotam-se as experiências ocorridas nos países centrais como se fossem as únicas possíveis, como se fossem a representação da verdade; visa-se explicar o que é interno do Brasil apenas a partir do exterior, de maneira que os resultados repetidas vezes geram violência em face da desconsideração da alteridade, ou seja, das peculiaridades locais (SANTOS JÚNIOR, 2013, p. 353). 
Ademais, a tendência importadora acrítica de matrizes teóricas dos Estados centrais é

um fenômeno histórico típico de países colonizados. Aliás, importa-se tudo, de pneus usados a ideias. Não raras vezes, o lixo é trazido como luxo. Ou o luxo aqui é lixo porque as realidades social, política, histórica, econômica e jurídica são diversas. Claro, portanto, que, quando se importam doutrinas estrangeiras produzidas em um contexto completamente diferente do nosso, ocorrem contradições insuperáveis (SANTOS JÚNIOR, 2013, p. 356).

A aceitação dos discursos criados a partir da realidade do centro, o qual possui uma conjuntura diversa, acarreta verdadeira desconsideração das peculiaridades locais (situação social, econômica, histórica, política e jurídica) dos Estados periféricos, e esta desvalorização fere o princípio da dignidade da pessoa humana e da igualdade (SANTOS JÚNIOR, 2013, p. 374).

Além da importação do sistema jurídico propriamente dito, sem se preocupar com os diversos aspectos que compõem a estrutura social brasileira, o direito continua sendo invadido pela introdução de teorias, de figuras e de institutos externos na tentativa de resolver mazelas e falhas internas. Não se pretende discutir a magnitude das teorias ou a sua relevância, o que se aspira refletir é que um conceito criado em um determinado contexto pode ser esplêndido, mas nem sempre é o mais adequado em outro.

É prudente exemplificar: ambas de Robert Alexy (alemão), a teoria da argumentação jurídica e a teoria dos direitos fundamentais, ao que tudo autoriza crer, inspiraram o legislador brasileiro na elaboração dos $\S \S 1^{\circ}$ e $2^{\circ}$ do artigo 489 do Código de Processo Civil (Lei 13.105 de março de 2015) (TRINDADE; DUARTE NETO, 2017, p. 1046).

A teoria da argumentação jurídica de Robert Alexy, em termos simplificados, afigura como uma teoria procedimental, formada por um sistema de regras que tem por objetivo a correção dos enunciados normativos. Isto remete que a argumentação jurídica é caracterizada "por seu relacionamento com a lei válida; contudo, isso precisa ser determinado. Esta teoria apresenta como fio condutor, portanto, a tensão entre facticidade e validade ou, mais especificamente, entre o princípio da segurança jurídica e a pretensão à correção das decisões" (MOTA; PEREIRA, 2012, p. 26).

Já a teoria dos direitos fundamentais de Robert Alexy, também de maneira reduzida, retrata como principal diferenciação teorético-estrutural a distinção entre regras e princípios. Esta distinção "é a base da teoria da fundamentação no âmbito dos direitos fundamentais e uma chave para a solução de problemas centrais da dogmática dos direitos fundamentais" (ALEXY, 2008, p. $85)$.

Isto posto, cabe transcrever o artigo 489 do Código de Processo Civil brasileiro de modo integral para evitar qualquer óbice:

Art. 489. São elementos essenciais da sentença:

I - o relatório, que conterá os nomes das partes, a identificação do caso, com a suma do pedido e da contestação, e o registro das principais ocorrências havidas no andamento do processo;

II - os fundamentos, em que o juiz analisará as questões de fato e de direito;

III - o dispositivo, em que o juiz resolverá as questões principais que as partes lhe submeterem.

$\S 1^{\circ}$ Não se considera fundamentada qualquer decisão judicial, seja ela interlocutória, sentença ou acórdão, que:

I - se limitar à indicação, à reprodução ou à paráfrase de ato normativo, sem explicar sua relação com a causa ou a questão decidida;

II - empregar conceitos jurídicos indeterminados, sem explicar o motivo concreto de sua incidência no caso;

III - invocar motivos que se prestariam a justificar qualquer outra decisão; 
IV - não enfrentar todos os argumentos deduzidos no processo capazes de, em tese, infirmar a conclusão adotada pelo julgador;

V - se limitar a invocar precedente ou enunciado de súmula, sem identificar seus fundamentos determinantes nem demonstrar que o caso sob julgamento se ajusta àqueles fundamentos;

VI - deixar de seguir enunciado de súmula, jurisprudência ou precedente invocado pela parte, sem demonstrar a existência de distinção no caso em julgamento ou a superação do entendimento.

$\S 2^{\circ}$ No caso de colisão entre normas, o juiz deve justificar o objeto e os critérios gerais da ponderação efetuada, enunciando as razões que autorizam a interferência na norma afastada e as premissas fáticas que fundamentam a conclusão.

$\S 3^{\circ}$ A decisão judicial deve ser interpretada a partir da conjugação de todos os seus elementos e em conformidade com o princípio da boa-fé.

Sendo assim, ao incorporar à legislação a ponderação com a finalidade de resolver os casos de colusão de normas (vide art. 489 §2 do Código de Processo Civil brasileiro),

o legislador incorreu em flagrante confusão conceitual, à revelia das formulações contidas na teoria dos direitos fundamentais, conferindo aos juízes uma "carta branca", uma vez que bastaria sua justificação do objeto e dos critérios aplicados para o sopesamento. A institucionalização dessa técnica, cujo emprego casuístico, até então, ampliava a discricionariedade dos julgadores, revela-se negativa e nociva - portanto, um desacerto do legislador - à medida que, não havendo padrão equivalente à fórmula de peso, terminará por alargar as margens de subjetividade e, consequentemente, de discricionariedade judicial. Se a vulgata da ponderação era uma realidade, no Brasil, antes mesmo do advento novo do Código de Processo Civil, a tendência é que, com sua previsão legal, a aplicação dessa técnica ganhe ainda mais força. E isso pode ser prejudicial a uma prestação jurisdicional democrática (TRINDADE; DUARTE NETO, 2017, p. 1065).

$\mathrm{O}$ que se quer dizer é que uma teoria jurídica não pode ser utilizada como remédio universal, cada sociedade é dotada de particularidades e nem sempre o que é adequado para um país também serve para satisfazer as necessidades de outro. Outra situação amplamente conhecida em que há infiltração de teoria estrangeira no direito brasileiro de forma imperfeita é a questão dos precedentes, situação na qual há a entrada de aspectos do sistema de common law no de civil law. O direito brasileiro é norteado pelos princípios da civil law, um sistema que é caracterizado como legalista, no entanto, nos últimos anos é possível perceber que decisões emanadas do Poder Judiciário estão sendo valoradas também como fonte criativa do direito, fator que sugere uma aproximação com alguns princípios do sistema da common law (MARINS, 2020).

Importa esclarecer que a teoria dos precedentes, originária do direito inglês, possui como ideia a força vinculantes de decisões emanadas pelos julgadores em casos análogos, de fato ou de direito. Como o sistema norte-americano é orientado pela common law, verifica-se na referida teoria a possibilidade de prever o resultado da demanda e, assim, o equilíbrio do Poder Judiciário. Por conseguinte, a sustentação da teoria não é outra senão a formação de um precedente judicial pelos tribunais superiores com força vinculante aos tribunais inferiores (MENEZES, 2017, p. 126127).

Quanto aos precedentes no Brasil, importa dizer que estes nem sempre terão natureza obrigatória, vinculante para as demais jurisdições. Logo, cabe descrever três implicações dos precedentes no direito brasileiro: a primeira delas é o efeito convincente, o qual considera o efeito ínfimo do precedente; enquanto que a segunda implicação é o efeito impeditivo, de modo que alguns precedentes, se forem ressalvados, obstam recursos para argumentá-los; por fim, a terceira implicação do precedente é o efeito vinculante ou normativo, ou seja, existem alguns precedentes 
que devem ser, obrigatoriamente, seguidos por todos os tribunais, como as súmulas vinculantes e as súmulas editadas pelos tribunais que vinculam cada um (MENEZES, 2017, p. 130).

Isto colocado, evidente que nem todas as importações são negativas, porém é preciso adaptar e neste processo de ajuste podem acontecer custosos equívocos, de modo que talvez fosse mais descomplicado utilizar o direito emanado do próprio Brasil para resolver reveses, o que autoriza, inclusive, refletir sobre a ampliação da pluralidade jurídica como forma de dizer o direito de acordo com as características de cada nação. Sendo assim, como consequência da presente importação de teorias jurídicas euro-americanas no direito brasileiro há a visibilidade enfraquecida do próprio direito brasileiro, que se apresenta inapto para o desenvolvimento de teorias autênticas, fazendo com o direito pátrio tenha sua personalidade debilitada. Ademais, outro efeito da mencionada importação é o afastamento da conquista do pluralismo jurídico, já que o próprio direito estatal é subjugado ao exterior, restando pouca ou nenhuma atuação para o direito advindo dos costumes. Além disso, há casos em que a figura estrangeira que se está incorporando ao direito brasileiro foi mal traduzida ou descontextualizada, acarretando consequências tão ruins quanto as que acontecem quando as figuras importadas se encontram em estados evolutivos sistêmicos diversos ou quando as condições normativas locais são impeditivas da adaptação da teoria trazida, ou seja, nos casos em que a realidade social, econômica, normativa, cultural, jurídica, etc., do país de origem da teoria é dessemelhante do país afetado. O questionamento que se faz, então, é: é possível encontrar desenlaces jurídicos a partir das referências do pluralismo jurídico e, portanto, buscar construir soluções na cultura brasileira ao invés de ir procurar teorias, figuras e institutos jurídicos no exterior?

\section{A CONSIDERAÇÃO DAS NAÇÕES BRASILEIRAS EM PROL DA CONSTRUÇÃO DE INSTRUMENTOS JURÍDICOS PRÓPRIOS DO BRASIL}

Uma síntese do exposto pode ser assim redigida: no Brasil o pluralismo jurídico não é constitucionalmente reconhecido e são importadas de forma sinuosa teorias euro-americanas do direito em detrimento de explorar o potencial jurídico a partir da essência cultural nacional. A partir destas duas premissas anteriormente desenvolvidas se pode estabelecer que referida importação de teorias, figuras e institutos jurídicos combate o progresso da emancipação do pluralismo jurídico presente no constitucionalismo latino-americano, constitucionalismo que o ordenamento jurídico brasileiro pertence, uma vez que referido fenômeno abre as portas para estabelecer o pluralismo jurídico e, no sentido contrário, o direito brasileiro importa com certa constância teorias externas para resolver problemas internos.

Sendo assim, evidente que a diversidade da formação do povo brasileiro precisa ser levada em consideração e, por mais este motivo, resta claro que o pluralismo jurídico deveria ser instigado e aflorado. Cabe evidenciar que o povo brasileiro, oriundo de diferentes grupos étnicos-raciais (indígenas, africanos, europeus, asiáticos), construiu sua identidade e aprendeu a transmitir a visão de mundo que se expressa nos valores, posturas e atitudes assumidas, nos princípios que defendem e nas ações que empreendem (SILVA, 2007, p. 491). Verdade é que a sociedade brasileira sempre foi multicultural, isto é, sempre foi composta por grupos étnicos-raciais diversos, que possuem culturas e organizações particulares, sejam indígenas ou pessoas escravizadas advindas da África (as quais foram compulsoriamente trazidas ao Brasil e nutriram consigo sabedorias e conhecimentos valorosos para todos os humanos) (SILVA, 2007, p. 493). Fato é que a relegação acerca das experiências de ser, viver, pensar e realizar dos indígenas, descendentes de africanos, etc. faz com que se viva em uma sociedade monocultural. Esta visão afasta a capacidade de corrigir a ilusão da democracia racial, de vencer determinações de um sistema centrado em uma única raiz étnica-racial (SILVA, 2007, p. 501). 
Darcy Ribeiro (1995, p. 126) explica que

o processo de formação dos povos americanos tem especificidades que desafiam a explicação Por que alguns deles, até mais pobres na etapa colonial, progrediram aceleradamente, integrando-se de forma dinâmica e eficaz na revolução industrial, enquanto outros se atrasaram e ainda se esforçam por modernizar-se? Evidentemente, os povos transplantados, cuja identidade étnica já veio perfeitamente definida da Europa, encontram em sua própria configuração facilidades de incorporar-se a uma nova civilização surgida no seio de suas matrizes. Outro é o caso de povos que estavam se fazendo como uma configuração totalmente diferente de suas matrizes, que enfrentava a tarefa de difundir os povos que reuniu, tão diversos uns dos outros. É tarefa sua, inclusive, definir sua identidade étnica, a qual não pode ser a de meros europeus de ultramar.

É importante ressaltar que a gente variada que se juntou no Brasil passa tanto pela "anulação das identificações étnicas de índios, africanos e europeus, como pela indiferenciação entre as várias formas de mestiçagem, como os mulatos (negros com brancos), caboclos (brancos com índios), ou curibocas (negros com índios)." (RIBEIRO, 1995, p. 133). Não é desejável anular as particularidades e formar uma única nação brasileira, a riqueza é justamente a individualidade, a miscigenação é que faz do Brasil um país único. Evidente que o Brasil possui uma capacidade para impulsionar a pluralidade jurídica e tornar a diversidade da composição do povo brasileiro um elemento fundamental para que o direito (estatal ou consuetudinário) possa ser empregado da forma mais adequada ao caso e, assim, promover a justiça e a paz social.

Cumpre esclarecer que não se propõe ignorar toda a construção de direito estatal feita a partir das diretrizes ocidentais, as quais hodiernamente recebem no Brasil, inclusive, matizes de institutos da common law. O que se intenta fomentar é a valorização da diversidade e da cultura brasileira a partir da solidificação do pluralismo jurídico, bem como do enaltecimento da produção dos juristas brasileiros a partir das vivências e das experiências nacionais. Além disso, urge cessar o pensamento de que o que é importado (incluindo construções jurídicas) é melhor e que o Brasil tem o dever de adaptar, independente dos custos e das consequências, as teorias desenvolvidas nos países centrais, teorias que nem sempre são as mais indicadas para a realidade social brasileira, que é periférica.

Por fim, destaca-se que foi Nelson Rodrigues quem cunhou por primeiro a expressão "complexo de vira-latas" para a designar o estado de inferioridade em que se colocam os brasileiros, uma vez que dentro dos países lusófonos, o Brasil recebe destaque por aspectos peculiares, como a constante mania do povo se autodepreciar frente aos demais (OLIVEIRA JUNIOR, 2019, p. 01). A fim de afastar a praxe de importar teorias euro-americanas do direito na ordem jurídica brasileira, propõe-se que o projeto emancipador do pluralismo jurídico seja considerado como uma opção real e plausível para fomentar a produção de teorias, figuras e institutos internos do país, em especial a partir do reconhecimento da diversidade cultural e da admissão que o direito estatal, de origem ocidental, não deveria ser considerado singular, uma vez que o Brasil é um país dotado de nações diversificadas que precisam obter respeito para que seus valores e preceitos sejam reconhecidos.

\section{CONSIDERAÇÕES FINAIS}

Não é novidade que o Brasil, assim como os demais países da América Latina, está em uma condição periférica em relação aos países do centro, ou seja, aos países já desenvolvidos. Uma das razões para o Brasil tardar o progresso é o fato de que foi colonizado e, portanto, por muito tempo padeceu sob uma exploração intensiva e explícita, sobretudo no que diz respeito aos recursos 
naturais, bem como foi fortemente influenciado pela cultura ocidental. Apesar de ser independente há quase duzentos anos, o Brasil ainda nos dias atuais carrega incontáveis cicatrizes do período colonial, inclusive no âmbito jurídico. Percebe-se que o sistema jurídico brasileiro, civil law, reflete o ocidental e, em muitas questões, não consegue se libertar dos liames externos para realizar a construção e a solidificação de entendimentos particulares em muitas temáticas.

Uma das formas que possibilitaria ao Brasil afastar a reprodução sinuosa e confusa de muitas teorias criadas em realidades e contextos distintos seria adotar o pluralismo jurídico, já que o pluralismo tem um caráter emancipador em relação as diretrizes ocidentais e, portanto, possibilitaria ao Brasil, um país formado por diversas nações (indígenas, africanos, asiáticos, etc.) aceitar que dois ou mais sistemas jurídicos tenham eficácia, ao mesmo tempo, dentro do território nacional, o que permitiria uma profusão das soluções para problemas que alcançam o plano jurídico.

Ocorre que, como outrora aludido, a Constituição Federal vigente no Brasil, a qual foi promulgada no ano de 1988 , pertence sim ao movimento nominado constitucionalismo latinoamericano, mas não traz em seu texto a possibilidade de pluralismo jurídico viger, visto que o reconhecimento do pluralismo se deu na terceira fase do fenômeno constitucional, de maneira que a Constituição Federal do Brasil não se encontra contemplada por esta possibilidade por ser anterior. Contudo, como sugerido, há a possibilidade de mudança do artigo $1^{\circ}$ da Carta a fim de inserir a legitimação do pluralismo jurídico no Brasil.

Outrossim, cabe ressaltar que não se critica a teoria da argumentação jurídica e a teoria dos direitos fundamentais de Robert Alexy, brilhante no contexto alemão, nem mesmo a valia dos precedentes para o sistema do common law. O que se questiona é a importação destas para o ordenamento jurídico brasileiro, como dito, um país em desenvolvimento com um contexto socioeconômico turbulento, diverso das economias desenvolvidas nas quais as teorias foram e são criadas. Destarte, é possível inferir que a importação de teorias euro-americanas no direito brasileiro atravanca o encargo emancipador do pluralismo jurídico. Além do mais, acredita-se que a emancipação ofertada pelo pluralismo jurídico compreende a capacidade de abrir os caminhos para que o pensamento jurídico brasileiro seja devidamente valorizado, uma vez que a possibilidade de dizer o direito a partir do reconhecimento relatado da cultura local é elementar para afastar a ânsia de valorizar e enaltecer o que vem do exterior e cessar a falta de prestígio das criações internas.

\section{REFERÊNCIAS}

ALEXY, Robert. Teoria dos Direitos Fundamentais. Tradução de Viroílio Afonso da Silva da $5^{\text {a }}$ edição alemã Theorie der Grundrechte publicada pela Suhrkamp Verlag (2006). Direitos reservados desta edição por Malheiros Editores Ltda. Impresso no Brasil 04.2008.

COLAÇO, Thais Luzia. Pluralismo jurídico e o direito indígena na América Latina: uma proposta de emenda constitucional no Brasil. In: WOLKMER, Antonio Carlos; LIXA, Ivone Fernandes M. (Orgs.) Constitucionalismo, descolonización y pluralismo jurídico en América Latina. Aguascalientes: CENEJUS/Florianópolis: UFSC-NEPE, 2015.

CURI, Melissa Volpato. O direito consuetudinário dos povos indígenas e o pluralismo jurídico. Espaço Ameríndio, Porto Alegre, v. 6, n. 2, p. 230-247, jul./dez. 2012.

FAJARDO, Raquel Yrigoyen. Pluralismo jurídico, derecho indígena y jurisdicción especial en los países andinos. EL OTRO DERECHO, número 30. Junio de 2004. ILSA, Bogotá D.C., Colombia. 
FAJARDO, Raquel Z. Yrigoyen. El horizonte del constitucionalismo pluralista: del multiculturalismo a la descolonización. In: El derecho en América Latina: un mapa para el pensamiento jurídico del siglo XXI. Coordinado por César Rodríguez Garavito. $1^{\mathrm{a}}$ ed. Buenos Aires: Siglo Veintiuno Editores, 2011.

FERRAZZO, Débora. Pluralismo jurídico e deslinde jurisdicional na Bolívia: a atuação do Tribunal Constitucional Plurinacional no controle de constitucionalidade. In: WOLKMER, Antonio Carlos; LIXA, Ivone Fernandes M. (Orgs.) Constitucionalismo, descolonización y pluralismo jurídico en América Latina. Aguascalientes: CENEJUS/Florianópolis: UFSC-NEPE, 2015.

HOEKEMA, André J. Hacia un pluralismo jurídico formal de tipo igualitario. EL OTRO DERECHO, número 26-27. Abril de 2002. ILSA, Bogotá D.C., Colombia.

LUNELLI, Isabella Cristina. Etnocentrismo jurídico, colonialidade e descolonização. In: WOLKMER, Antonio Carlos; LIXA, Ivone Fernandes M. (Orgs.) Constitucionalismo, descolonización y pluralismo jurídico en América Latina. Aguascalientes: CENEJUS/Florianópolis: UFSC-NEPE, 2015.

MARINS, Lucas Belloc. A sistemática da teoria do precedente judicial e a gradual introdução de princípios da common law no Direito brasileiro. Academia Brasileira de Direito Processual Civil. Disponível em: < http://www.abdpc.org.br/abdpc/artigos/Lucas\%20Belloc\%20Marins\%20\%20vers\%C3\%A3o\%20final.pdf > Acesso em: 02 mar. 2020

MENEZES, Eudes Regina Ferreira de. Precedentes judiciais no Código de Processo Civil de 2015. Revista Científica da FASETE 2017.1.

MOTA, Mauricio Jorge Pereira da; PEREIRA, Daniel Queiroz. Argumentação jurídica, ponderação e representatividade argumentativa na obra de Robert Alexy. Revista Quaestio Iuris, vol.05, nº1., 2012, ISSN 1516-0351 p. 21-50.

OLIVEIRA JUNIOR, Eduardo F. de. Do complexo de vira-lata ao multiculturalismo cru. Revista Científica Doctum: Multidisciplinar. DOCTUM. Caratinga. v. 1, n. $2,2019$.

RIBEIRO, Darcy. O Povo Brasileiro: A formação e o sentido do Brasil. Segunda Edição. Companhia das Letras. São Paulo, 1995.

SANTOS JÚNIOR, Rosivaldo Toscano dos. Juristas colonizados? Crítica à importação de teorias jurídicas. Revista da AJURIS - v. 40 - n. 132 - Dezembro 2013.

SILVA, Petronilha Beatriz. Aprender, ensinar e relações étnico-raciais no Brasil. Educação, vol. XXX, núm. 63, setembro-dezembro, 2007.

SPAREMBERGER, Raquel Fabiana Lopes. O conhecimento jurídico colonial e o subalterno silenciado: um olhar para o pluralismo jurídico. In: WOLKMER, Antonio Carlos; LIXA, Ivone Fernandes M. (Orgs.) Constitucionalismo, descolonización y pluralismo jurídico en América Latina. Aguascalientes: CENEJUS/Florianópolis: UFSC-NEPE, 2015.

TRINDADE, André Karam; DUARTE NETO, João Carneiro. Os (des)acertos do legislador na 
"positivação" das teorias de Robert Alexy no direito processual civil brasileiro. Revista Eletrônica do Curso de Direito da UFSM www.ufsm.br/revistadireito v. 12, n. 3 / 2017.

VERÁS NETO, Francisco Quintanilha. O pluralismo jurídico comunitário participativo e economia solidária: o horizonte utópico do cooperativismo popular na praxis de uma democracia fundada na libertação latino-americana. In: WOLKMER, Antonio Carlos; LIXA, Ivone Fernandes M. (Orgs.) Constitucionalismo, descolonización y pluralismo jurídico en América Latina. Aguascalientes: CENEJUS/Florianópolis: UFSC-NEPE, 2015.

WOLKMER, Antonio Carlos. Pluralismo jurídico: nuevo marco emancipatorio en América Latina. Doc. de trabajo / Informes. Ética; Derecho; Sociología; Legitimidad; Pluralismo; Aspectos jurídicos; Solidaridad; Democratización; Sujetos sociales; América Latina; CENEJUS, 2003.

WOLKMER, Antonio Carlos; FAGUNDES, Lucas Machado. Tendências contemporâneas do constitucionalismo latino-americano: Estado plurinacional e pluralismo jurídico. Pensar, Fortaleza, v. 16, n. 2, p. 371-408, jul./dez. 2011. 